\title{
ALEGORÍAS CONTEMPORÁNEAS
}

Artículo de reflexión

\section{Alberto Carlos Romero Moscoso}

Universidad Jorge Tadeo Lozano / alberto.romero@utadeo.edu.co

Actualmente adelanta Doctorado en Estudios Sociales. Es Magíster en Filosofía de la Universidad del Rosario, Especialista en Cultura Visual de la Universidad de Barcelona, Licenciado en Artes de la Universidad de París I (Francia) y Maestro en Artes Plásticas de la Universidad Nacional de Colombia. Como artista plástico ha obtenido el Premio Nacional de Arte Joven y el Premio Nacional Artes del Fuego, además de distinciones y premios de carácter regional y local; ha adelantado exposiciones nacionales y en las ciudades de Barcelona y París, y ha participado como jurado en convocatorias públicas en arte, diseño y video así como presentado ponencias y conferencias en eventos nacionales. Coautor de los libros Poéticas y críticas del devenir y Estética, vida artificial y biopolítica. 
ROMERO A, (2014) Alegorías contemporáneas. Calle14,8 (12), 122-132.

\section{RESUMEN}

Con fundamento en las ideas de vivencia, alegoría y símbolo, propias de una estructura tradicional de interpretación, se propone que el cambio en el equipamiento conceptual para abordar la obra de arte como lugar de conocimiento no proviene de las herramientas que se dispongan para la interpretación. Partiendo de la perspectiva hermenéutica del arte contemporáneo (entendida esta como el fenómeno de la comprensión y correcta interpretación de textos, pero también de objetos de la experiencia), este artículo se ocupa del arte como forma de la experiencia en la que se expresa una verdad que no puede ser verificada con los medios de la perspectiva científica, pero que puede ser objeto de interpretación.

\section{PALABRAS CLAVES}

Alegoría, arte contemporáneo, hermenéutica

\section{CONTEMPORARY ALLEGORIES}

\section{ABSTRACT}

Based on the ideas of experience, allegory and symbol, which are typical of a traditional structure of interpretation, we propose that the change in the conceptual equipment to address the work of art as a place of knowledge does not come from the tools used in the interpretation. Starting from a perspective of contemporary art grounded in hermeneutics (the phenomenon of understanding and correctly interpreting texts, but also objects of experience), this article deals with art as an experience in which a truth is expressed that cannot be verified by means of the scientific perspective, but can become an object of interpretation.

\section{KEYWORDS}

Allegory, contemporary art, hermeneutics

\section{ALLÉGORIES CONTEMPORAINES}

\section{RÉSUMÉ}

Sur base des idées d'expérience, d'allégorie et de symbole, propres à une structure traditionnelle de l'interprétation, il est proposé que le changement de l'équipement conceptuel pour aborder l'œuvre d'art comme un lieu de connaissance n'émane pas des outils disponibles pour l'interprétation. Partant de la perspective herméneutique de l'art contemporain (entendue comme le phénomène de la compréhension et de l'interprétation correcte de textes, mais aussi d'objets de l'expérience), cet article traite de l'art comme une forme d'expérience dans laquelle une vérité est exprimée ne pouvant être vérifiée à l'aide du point de vue scientifique, mais qui peut être l'objet d'interprétation. 


\section{MOTS CLÉS}

Allégorie, art contemporain, herméneutique

\section{ALEGORIAS CONTEMPORÂNEAS}

\section{RESUMO}

Com fundamento nas ideias de vivência, alegoria e símbolo, próprias de uma estrutura tradicional de interpretação, propõe-se que o câmbio no equipamento conceitual para a abordagem da obra de arte como lugar de conhecimento não provêm das ferramentas que se disponham para a interpretação. Partindo da perspectiva hermenêutica da arte contemporânea (entendida esta como o fenômeno da compreensão e correta interpretação de textos, mas também de objetos de experiência), este artigo se ocupa da arte como forma da experiência na qual se expressa a verdade que não pode ser verificada com os meios da perspectiva científica, mas que pode ser objeto de interpretação.

PALAVRAS-CHAVE:

Alegoria, arte contemporâneo, hermenêutica.

\section{KUNAURA IMA RIGCHA KAGTA}

\section{SUGLLAPI MAILLA KILKAILLATA}

Sutipa iuiaita kawachispa kai rigchaikuna. kasapimi iachari iachanchu kawachingapa sugkunata, suura kawachinkuna samaiachispa paikuna ima kaugsaskata iachagkunallamí ningakuna. chi rigchapi imata willaku.

\section{IMA SUTI RIMAI SIMI}

Chi rigcha imata ka, Kunaura rigcha- rigcha, hermenéutica. 
Mirar una obra de arte permite que en su comprensión penetre algo más, eso implica interpretar. (Arte y verdad de palabra)

Este texto se ocupará de examinar la perspectiva hermenéutica del arte contemporáneo, entendida la hermenéutica como el fenómeno de la comprensión y la correcta interpretación de textos o de otros objetos de la experiencia. Es decir, se ocupará del arte como forma de la experiencia en la que se expresa una verdad que no puede ser verificada con los medios de la perspectiva científica, pero que puede ser objeto de interpretación.

El siguiente texto, entonces, tratará de desarrollar la hipótesis según la cual una obra de arte contemporáneo puede ser interpretada bajo algunas de las nociones que propone H. G. Gadamer, aunque es sabido que las propuso para una circunstancia reducida del arte, la pintura. Según el orden que se llevará en el texto, las nociones consideradas son: primero, el saber práctico, bajo la idea del gusto; segundo, las nociones de alegoría, símbolo, juego y vivencia y, por último, se intentará concluir ajustando las nociones a la valoración del arte contemporáneo.

\section{Del saber práctico a la idea de gusto}

Digamos para comenzar, y aunque parezca una obviedad, que la experiencia hermenéutica considera argumentos distintos a aquellos de la razón teórica y que existen, bien sabemos, formas y maneras de conocimiento que no responden a la demostración. De manera que, por ejemplo, el conocimiento propio de la obra de arte no puede ser objeto de demostraciones experimentales; tampoco puede elaborarse una teoría en torno a la obra de arte que la explique a partir de la razón, es decir, que la advierta como conocimiento independiente de la experiencia.
En lo que se refiere a la obra de arte, Gadamer va a llamar al saber propio de esta, saber práctico: "el saber práctico es una forma de saber distinto, es un sentido que se adquiere a través de la comunidad y se comprende desde la tradición y la historia" (2005: 53). Y aunque el saber práctico puede referirse también a la moral, nos concentraremos en su asociación a la obra de arte.

Con el objeto de ordenar ese saber práctico como suelo de las ciencias del espíritu, Gadamer despliega cuatro nociones: la primera, la formación, que designa el modo específicamente humano de dar forma, de configurar el entorno. La segunda, el sentido común, sentido que se adquiere en la relación con los otros y proporciona una sensibilidad para las verdades comunes, que además son verdades útiles para todos los hombres en todo tiempo, transformándose así, de verdades comunes en verdades sensibles. La tercera noción es la capacidad de juicio, que se entiende como la manera de aplicar correctamente lo aprendido. Si bien el entendimiento común (o sentido común) se relaciona con la capacidad de juzgar, este no desempeña el menor papel en lo que podría llamarse una capacidad de juicio.

Habría entonces que decir, en cuanto a los juicios morales y estéticos, que su carácter es un sentimiento (sabemos que lo bello, por ejemplo, es un sentimiento). Para Kant, como es conocido, el juicio estético es un juicio de gusto, es decir, el juicio de gusto no es un juicio de conocimiento; no es lógico, sino estético, su base determinante es enteramente subjetiva (Kant, 1991: 209).

Ahora bien, la cuarta de las nociones, el gusto, sí tiene que ver con el saber práctico que arriba mencionamos y puede referir a la moral en la medida en que esta también se constituye en la comunidad desde la tradición y la historia. En ese sentido, la sociedad, como la entiende Gadamer, no se legitima por nacimiento sino por la comunidad de sus juicios, y el gusto, entonces, 


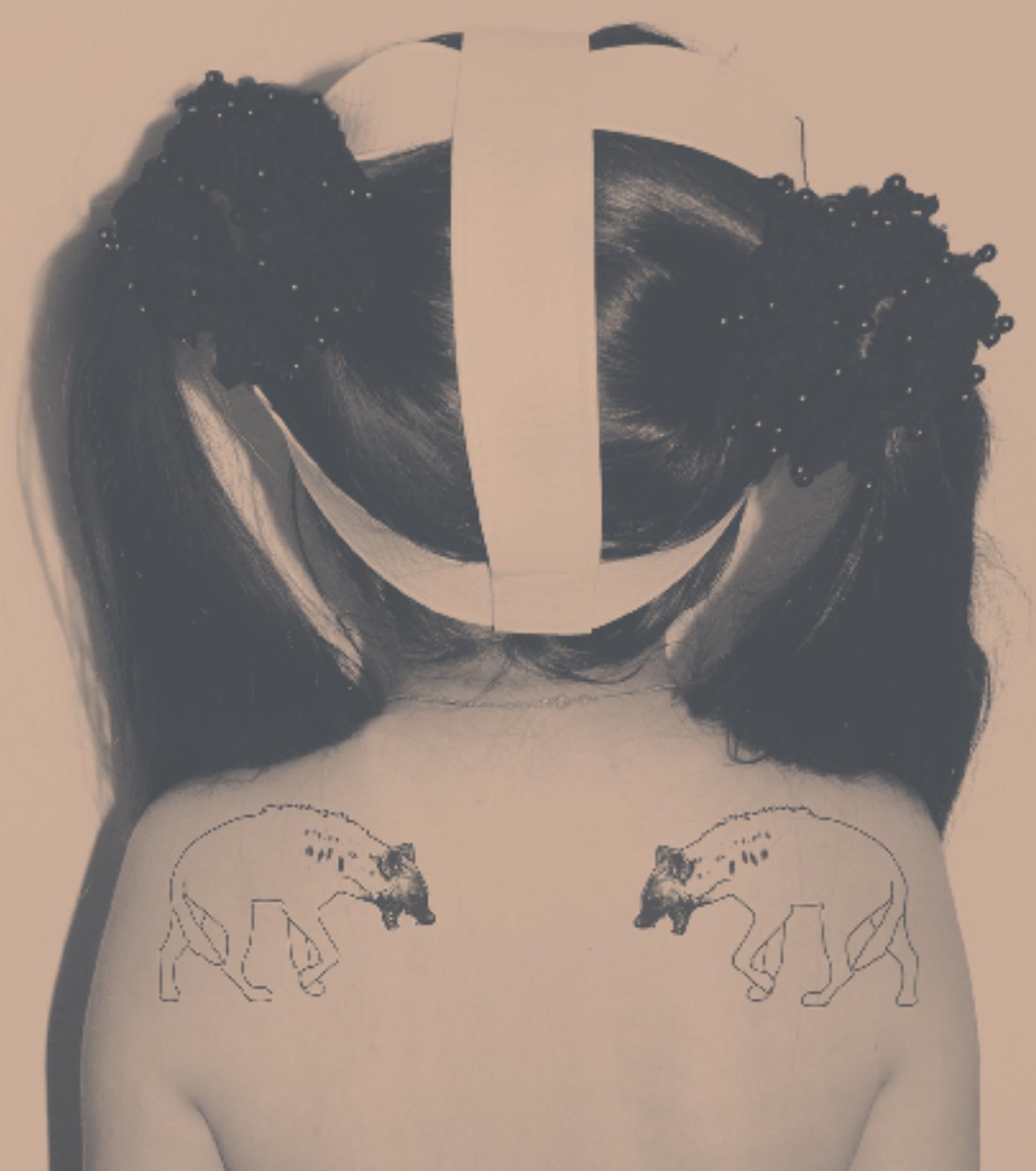


no es una cosa privada sino un fenómeno social de primer rango.

Con el concepto de gusto, además, se menciona una manera propia de conocer. El gusto no se limita a lo que es bello en la naturaleza y en el arte sino que abarca todo el ámbito de costumbres y convivencias. Se trata, entonces, de una capacidad de juicio no lógica sino estética (Gadamer, 2005: 38-73); es decir, se trata de un juicio estético, un juicio cuya determinante es subjetiva, como ya se dijo. Así, las posibilidades de demostración de la teoría racional no agotan el ámbito del conocimiento.

Desde las ideas anteriores parece posible acceder también al conocimiento propio de la obra de arte. Es así como, a partir del concepto de gusto, que se mencionó atrás referido a las ciencias del espíritu, es posible acceder a una discusión que puede aproximarse primero a la idea de belleza y, por esa vía, a la noción más tradicional de arte, que será fundamental para el propósito central de este texto.

Partimos de la idea según la cual la validez de lo bello no se puede derivar ni demostrar desde un principio general. Y, siguiendo a Gadamer, la idea de que "a nadie le cabe duda de que las disputas sobre cuestiones de gusto no pueden decidirse ni por argumentación ni por demostración" (Gadamer, 2005: 75) se articula, por ejemplo, con la obra de Alexander Melamid y Vilaly Komar, quienes a la mejor manera de las prácticas contemporáneas, construyen "la pintura más buscada"1 ${ }^{1}$ luego de un juicioso trabajo de mercadeo cuyo resultado son pinturas que se pueblan de los iconos de belleza, identidad y sentido particulares para cada comunidad.

Siguiendo el horizonte de salvar para el arte un lugar de conocimiento determinado por la interpretación, Gadamer inspecciona la doctrina kantiana del gusto y del genio, según la cual el libre juego de imaginación y entendimiento es una relación subjetiva y da como resultado el placer que se experimenta ante el objeto. También se ocupa de las teorías de la belleza libre y la belleza dependiente y de la teoría del ideal de belleza, que para esta tarea son fundamentales, en tanto de estas se desprende la idea según la cual para que algo guste como obra de arte, tiene que ser algo más que grato y de buen gusto. Es decir, si bien encontramos en una manera de representación moderna, por ejemplo un paisaje, que apela al tiempo al gusto general y

1 Ver www.komarandmelamid.org (1994-97). People's Choice Series. es aceptado como bueno, eso no implica que sea una obra de arte. En el propósito de que ese paisaje se convierta en una obra de arte contemporáneo debe, sin duda, aparecer algo que apunte mas allá, para lo cual nos sería útil como ejemplo, volver a Komar y Melamid y a sus paisajes, que invitan a una discusión sobre la cultura y la construcción misma de la idea de gusto, sobrepasando el lugar propio de la representación que, no sobra decir, bajo algunas consideraciones ha alcanzado sus límites.

En el mismo sentido, el formalismo del placer, que tiene que ver con la idea según la cual es en la forma donde debemos encontrar el placer y que ella puede ser fundamento, por ejemplo, de corrientes particulares de la historiografía del arte, como el arte óptico o el arte minimalista (pero no, por supuesto, de las maneras y estrategias generales del arte contemporáneo). De manera que se agota el ideal racionalista de la estética en tanto asuntos como la belleza se escaparían al intentar ordenar sus márgenes, y cualquier teoría universal devendría entonces corta, como es apenas evidente.

Despojado de su sentido representativo, que está sujeto a ideales tradicionales como el de armonía y belleza, el arte, dice Gadamer, podrá convertirse en un fenómeno autónomo. Su tarea ya no será la representación de los ideales de la naturaleza, sino el encuentro del hombre consigo mismo en la naturaleza, pero también, y sobre todo, en el mundo humano e histórico. La idea kantiana de que lo bello gusta sin conceptos, no impide en manera alguna que solo nos sintamos plenamente interesados por aquello que siendo bello nos habla con sentido. Es posible que en lo bello se agote nuestro interés y que este emerja nuevamente en el ejercicio de interpretar el sentido de la obra de arte, en el cual, además de la forma, se enuncian reflexiones sobre la condición humana. Así, es justamente el conocimiento de la ausencia de conceptos del gusto lo que puede llevarnos más allá de una mera estética del gusto (Gadamer, 2005: 83).

Finalmente, recordemos que para Kant el arte es más que una representación bella de una cosa: es representación de ideas estéticas, esto es, de algo que está más allá de todo concepto. Pero, “Una idea estética, además, no puede llegar a ser un conocimiento, porque es una intuición (de la imaginación) para la cual nunca se puede encontrar un concepto adecuado" (Kant, 1991: 302). La idea estética, en el arte representativo, tendría que ver, mejor, con el modelo, y la figura que constituye su expresión sería la copia. 
Así, la inspección del horizonte kantiano nos permite el transito del saber práctico a la idea de gusto y hace posible la formulación de la idea del arte como un ejercicio autónomo.

\section{La vivencia, el símbolo, la alegoría y el juego}

Para abordar la noción de vivencia, es necesario hacer dos anotaciones. La primera tiene que ver con la historia del término, que está referida al haber vivido, y la segunda, con su valor conceptual, que refiere por una parte a lo dado en la conciencia y por otra a la inmediatez, y que se aleja del intento de referirse a su significado. Para Gadamer, la vivencia estética representa la forma esencial de la vivencia en general.

Parece incluso que la determinación misma de la obra de arte es que se convierta en vivencia estética, esto es, que arranque al que la vive del nexo de su vida por la fuerza de la obra de arte y que sin embargo vuelva a referirlo al todo de su existencia. (Gadamer, 2005: 107)

La vivencia es la base epistemológica para todo conocimiento objetivo, es la forma de conocer las cosas objetivas, entre ellas la obra de arte. El arte, en tanto lugar de conocimiento objetivo, es vivencial, proviene de la vivencia y es su expresión. Esto se entiende como el arte autentico y la obra como la realización plena de la representación simbólica de la vida (Gadamer, 2005: 96-108), lo que puede fundamentarse, arqueológicamente, desde los conceptos de símbolo y alegoría. La alegoría tiene que ver con el hablar; para decir lo que se quiere, se dice algo distinto pero de manera que permita comprender lo que se quiere expresar. Es posible, entonces, que la mayor parte de la práctica artística del siglo XX y XXI, luego de los movimientos de vanguardia, tenga un carácter fuertemente alegórico; cualquiera de los fotomontajes políticos de John Heartfield y George Grosz, las obras de M. Broodthaers sobre Mallarmé o las obras fuertemente comprometidas de Hans Haacke, solo por citar algunos ejemplos, están claramente mostrando unas cosas, para finalmente decir otras². Es posible que la producción artística que hemos

2 En Formalismo e historicidad (Akal, 2004) Benjamín Buchloh desarrolla un capítulo a partir de la relación de las vanguardias de los años veinte con el concepto de alegoría en Walter Benjamín, con el objeto de rastrear esta idea hasta el arte contemporáneo. ("Procedimientos alegóricos: apropiación y montaje en el arte contemporáneo"). considerado relevante en el último tiempo disponga para la mirada un arsenal de imágenes amplio, pero que no sean esas imágenes lo que nos están invitando a ver.

El símbolo, por su parte, no está restringido a la esfera del habla, es su propio ser sensible el que tiene significado, y además vale como símbolo aquello en lo que se reconocen los miembros de una comunidad. De manera que el arte pop norteamericano, por ejemplo, es un arte esencialmente simbólico.

La alegoría y el símbolo, además, son importantes para el propósito que intentamos considerar, por el hecho de que su estructura común representa algo a través de otra cosa y, por lo tanto, se constituyen como fundamentales para el ejercicio de las artes representativas, pero también para el del arte contemporáneo. Lo que aparece ante nuestros ojos no es en realidad lo que se espera que veamos o lo que debemos ver. Por su parte, en Gadamer, los dos conceptos están vinculados con el ámbito religioso y el fundamento es que no es posible conocer lo divino sino a partir de lo sensible. Entonces, los dos conceptos "suponen un nexo metafísico de lo visible con lo invisible" (2005: 110): en el arte contemporáneo sería posible prescindir de lo visible para ver el arte.

El arte contemporáneo, entonces, hace visible en el sentido de que muestra lo que no está mostrando, y presenta formas de carácter alegórico o simbólico que, interpretadas por un espectador, le permitirán otorgar un sentido a un texto particular, inscrito en lo que estas formas sugieren o intiman como algún tipo de sospecha. Eduardo Kac ha logrado construir genéticamente un conejo cuya piel brilla por tener en sus genes una proteína verde fluorescente. Es posible que, inscrito en el ejercicio de la ciencia, el conejo (Alba) no encuentre mayor lugar a discusión, pero resulta ciertamente posible que, utilizada la obra para hacer visible, oriente la discusión hacia asuntos como el problema mismo de la vida en un mundo tecno-científico o hacia alguna otra reflexión, construida en la mirada (interpretativa) de la obra y en relación a asuntos que en la obra aparecen apenas como pistas o indicios.

La vivencia estética de una colectividad tiene que ver con rodearse de alegorías y símbolos, bien por ser significativos internamente en el caso del símbolo o por tener significaciones externas y artificiales en el de la alegoría. Cuando se establece el criterio de la alegoría vinculado a lo mítico religioso —en la historicidad del arte acudimos a las referencias de la tradición católica- 


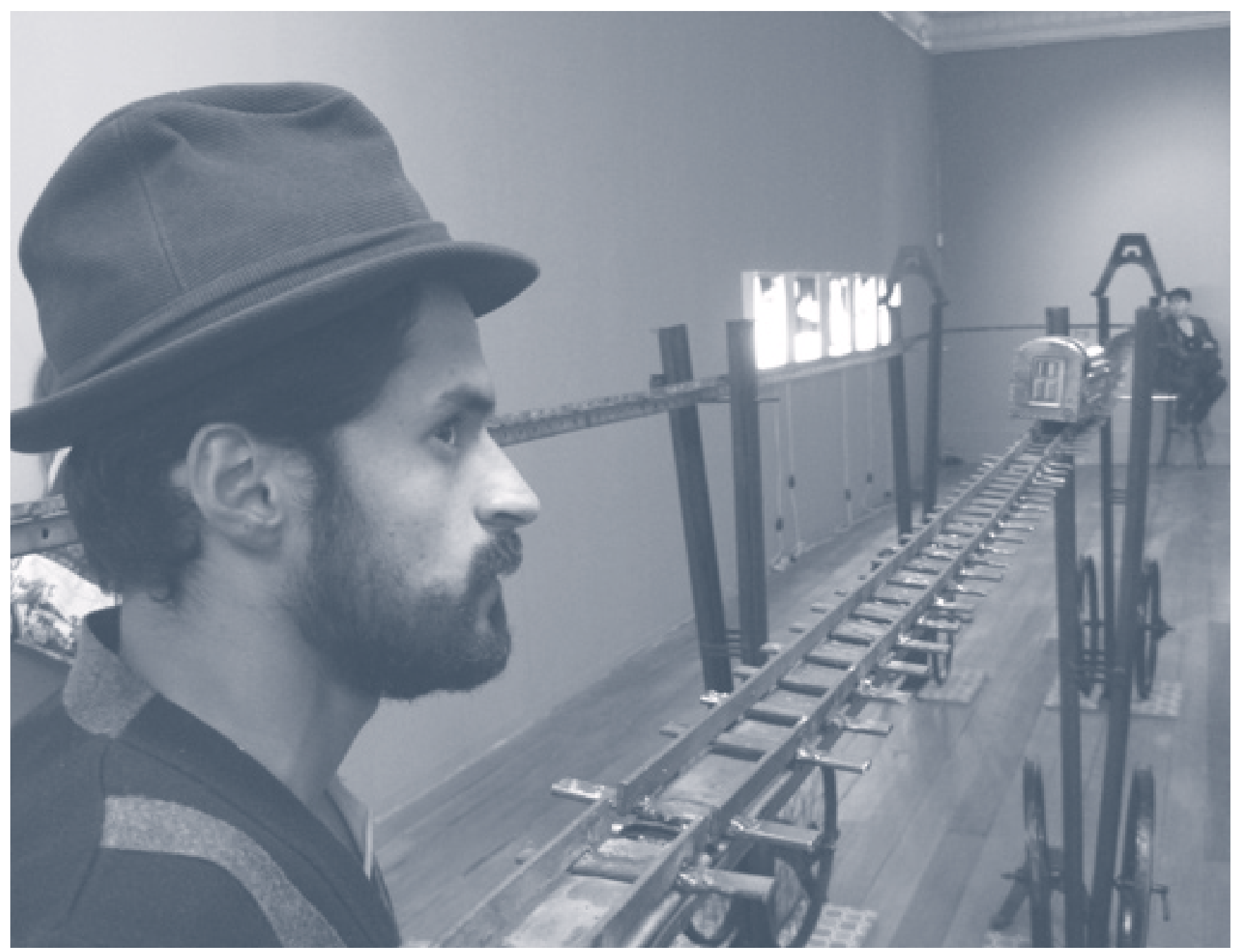

A Artista y obra en la Facultad de Artes ASAB. Fotografía: Marcos Roda

el arte representativo ordena su historia a partir de la puesta en escena de una serie de valores y códigos formales, vinculados con la doctrina y el dogma, que se hacen evidentes en la iconografía religiosa, al mismo tiempo que preparan el terreno para que el símbolo tenga una posición central en la filosofía del arte. Así, el concepto de símbolo se convierte en un principio estético universal, y la noción intenta la coincidencia entre la imagen y el sentido. Se reconocen, además, en la idea de símbolo relaciones con la estética del genio y de la vivencia. "La firmeza de la oposición conceptual entre el símbolo, que se ha desarrollado orgánicamente y la fría y racional alegoría, pierde su vinculatividad en cuanto se reconoce su vinculación con la estética del genio y de la vivencia." (Gadamer, 2005: 119)

Es así como la aproximación hermenéutica al arte contemporáneo considera que la irrupción de estas cuestiones implica una revisión fundamental de los conceptos estéticos de base en términos de la real transformación del aparato conceptual que permite la construcción de sentido desde la obra de arte. Transformación que vista con juicio no será otra cosa que la vuelta a las estrategias primeras de interpretación del arte. La obra de arte, que ya no pertenece al universo de las formas de la vida cotidiana de las comunidades, abandonó el prospero lugar en el que era reconocida por todos, sin recriminaciones ni exigencias y colonizó el universo de la estética informada y erudita, pero mantuvo las herramientas de consolidación de discurso más tradicionales. Lo que parece estar en juego es un cambio en los conceptos de gusto, de valoración y de conciencia estética.

En cualquier caso no cabe duda que las grandes épocas de la historia del arte fueron aquellas en las que la gente se rodeo, sin ninguna conciencia estética y sin nada parecido a nuestro concepto de arte, de configuraciones cuya función religiosa o profana en la vida era comprensible para todos y que nadie disfrutaba de manera puramente estética. (Gadamer, 1998a: 57) 
Si bien se hace énfasis en la idea según la cual lo que se ve no es la obra de arte sino el símbolo que la atraviesa, lo anterior permanece sujeto a discusión, en consideración a aquello que puede ser entendido como una conciencia estética (una de cuyas funciones es el juicio estético) y un concepto de arte, comprensibles para todos. Es decir, es claro que en las manifestaciones artísticas que se inscriben en la historia como instancias de relaciones de poder, se hace difícil la lectura del arte como un territorio sin requisitos para su acceso y desprovisto de connotaciones y valoraciones de otro orden: “El carácter ideológico de las obras de arte y los productos culturales se reconoce como extremadamente complejo, estando influida su determinación por factores económicos..." (Gadamer, 2005: 120). El arte es un lugar que determina complicadas estructuras sociales y es, a su vez, determinado por estas. Sus construcciones solo acuden al llamado demagógico a la comprensión en las intenciones de los movimientos que hacen el transito del siglo XIX al XX, que resultan, por vía de intentar cambiar el arte, proponiendo la transformación real del mundo.

El arte se convierte en un punto de vista propio, instintivo, en el que la realidad de la apariencia bella no es su objeto: la oposición entre arte y naturaleza es oposición entre apariencia y realidad. El arte se entiende como liberado de los espacios dados por la naturaleza y posible solo desde la voluntad del artista, donde la naturaleza puede ser enmascarada, ocultada o deformada y se funda un dominio propio y autónomo para el ejercicio del arte. Dominio en el que su propio construirse como práctica e indicar sus componentes -emoción, obra y genio (convertidos en referencias míticas del universo del arte) — reiteran su autonomía.

La sociedad, separada de sus tradiciones religiosas, espera del arte más de lo que corresponde. Son estos asuntos los que luego determinarán la pretensión de la tragedia del artista en el mundo (Gadamer, 2005: 128), ciertamente posible en la mayoría de figuras históricas del fin de la modernidad como Van Gogh, Ensor o Gauguin. Por lo demás, la discusión importante en el siglo XX gira en torno a la figura del artista, que destaca sobre la que pueda hacerse sobre su obra misma: desde las continuaciones de las vanguardias, pasando por Fluxus, hasta figuras iconográficas como Beuys o Manzini, el arte habla con mayor intensidad y entusiasmo del artista que de la propia obra.

Dicho lo anterior, la vivencia estética, como forma de conocer las cosas objetivas (entre estas la obra de arte) es indiferente respecto a que su objeto sea real o no y la conciencia estética posee una soberanía sobre todo.

Es así como la hermenéutica, que se presenta como un esfuerzo por comprender en principio lo que debe ser interpretado a partir de un texto, se emplea en lo que nos ocupa en la comprensión del arte y más precisamente en la compresión de obras de arte particulares. Razón por la cual se hace necesario dirigir la mirada al tránsito de la palabra a la imagen y de la representación al texto. "Solo cuando reconocemos lo representado estamos en condiciones de leer una imagen; en realidad $y$ en el fondo solo entonces hay tal imagen. Ver significa articular." (Gadamer, 2005: 132)

En lo que respecta a la obra de arte, el asunto parece estrecho, dada la referencia al arte figurativo, que sería el único en el cual el ejercicio de la representación concuerda con el mundo real, donde es posible reconocer lo representado. Y para reconocerlo es necesario que hablemos de una experiencia de la obra de arte y que esta experiencia sea reconocida como tal, lo que apunta a nombrarla como contenido de verdad; es decir, la experiencia de la obra de arte es la que permite participar de ella como conocimiento. "El contenido de verdad que posee toda experiencia del arte está reconocido aquí de una manera soberbia, y al mismo tiempo está desarrollada su mediación con la conciencia histórica. De este modo la estética se convierte en una historia de las concepciones del mundo, esto es, en una historia de la verdad tal y como esta se hace visible en el objeto del arte."(Gadamer, 2005: 139) La experiencia de la obra de arte implica un comprender y el comprender es interpretar; de este modo, la obra representa por sí misma un fenómeno hermenéutico.

Por último, respecto a la hermenéutica, Gadamer esboza una relación entre la idea de juego y la noción de arte, aunque referida a la poesía y a la música. En el juego, además, aparece un cierto carácter lúdico, lejos de las reglas y prescripciones del mundo cotidiano, pero útil en el sentido en que hace posible que el artista "no necesita como individuo, como conciencia pensante, saber expresamente lo que hace y lo que su obra va a decir." (2005: 180) El juego es representación y es, al mismo tiempo, construcción y mediación; “la representación, tiene que volver a reconocerse como el modo de ser de la obra de arte misma" (160). Para que exista representación debe reconocerse en ella algo; es allí donde la imitación y la copia parecen tener una tarea. La mimesis, venida de la teoría antigua del arte, hace que todo representar sea un juego en el que 
reconocer es jugar. Aunque las prácticas últimas no muestren su interés en representar el mundo tal cual este aparece, es decir, imitarlo, solo será posible para nosotros una lectura interpretativa de la obra de arte si ella se constituye en representación: "la obra de arte le dice algo a uno, y ello no solo del modo en que un documento histórico le dice algo al historiador: ella le dice algo a cada uno, como si se lo dijera expresamente a él..." (Gadamer, 1998: 59). Solo así, la obra de arte juega y al tiempo nos permite jugar.

Cualquier obra plástica tiene que poder experimentarse como ella misma, "inmediatamente" dice Gadamer (2005: 181). Es decir, sin necesidad de más mediaciones, y además debe ser experimentada a partir de la subjetividad. Gadamer entiende bajo esta idea solo la pintura sobre lienzo o tabla que no está vinculada a un lugar fijo y que se ofrece enteramente por sí misma en virtud del marco que la encuadra. Así, Gadamer entiende como obra plástica el cuadro. Dadas las fuertes explosiones que en el transcurso del siglo XX y XXI se suscitaron sobre el espacio de la pintura y en lo particular sobre el cuerpo mismo del cuadro, la noción parece no encarar lo que tiene que ver con las producciones contemporáneas. Sin embargo, la idea de que cualquier obra de arte se convierte en un cuadro alejada de su referencia material, puede sugerir el camino para la inspección de la obra de Gadamer en lo que respecta a la lectura del arte contemporáneo. Un dispositivo contemporáneo con carácter de instalación bien podría ser leído desde la perspectiva de lo que presenta a nuestra interpretación. Es un encuadramiento; en cualquier caso, una imagen.

Por otra parte las ideas de símbolo y alegoría parecen ser fundamentales, ya no solamente en lo que respecta a la traducción de códigos de la imagen o del encuadramiento, sino en lo que tiene que ver con la construcción esencialmente conceptual, es decir, en el propósito de la obra de arte de convertirse en la portadora de un ejercicio de pensamiento que se distancia de su aparecer formal y puede solo ser descifrado en su existencia metafórica.

\section{Referencias}

Buchloh, B (2004). Formalismo e historicidad. Madrid: Editorial Akal.

Gadamer, H.G (2005). Verdad y método. Salamanca: Ediciones Sígueme.

(1998). Arte y verdad de la palabra. Barcelona: Ediciones Paidós Ibérica.

(1998a). Estética y hermenéutica. Madrid:

Editorial Tecnos.

Kant, I. (1991). Crítica del juicio. México, D. F: Editorial Porrúa.

Wolff, J. (1997). La producción social del arte. Madrid: Ediciones Istmo. 